\title{
Editorial
}

\section{Clinical Legal Education: Innovating Legal Education in Europe}

Paul McKeown

Northumbria University, UK

\section{paul.mckeown@northumbria.ac.uk}

How often do we attend a conference, listen intently as various colleagues from around the world share their thoughts, their experiences, their ideas? How often, following the delivery of a paper, is the room electrified with discussion as clinical colleagues are energized with their own thoughts and ideas based upon what they have just heard. We take these thoughts and ideas, we debate them, we test them, we adapt them and we implement them into our own practice. The aim is to enrich and enhance our field. There is a problem however. Often, those thoughts and ideas, the content of the discussions remains with the people who attended that particular session of the conference. Many clinical colleagues may not have been able to attend the conference; those who did may have been attending a different session. As such, they have not been able to participate in the discussion.

The European Network for Clinical Legal Education held its $6^{\text {th }}$ Conference in Turin on $20^{\text {th }}$ and $21^{\text {st }}$ September 2018. We wanted to share some of the thoughts, ideas and experiences discussed throughout the course of the conference to open up the debate 
Special Issue: European Network for Clinical Legal Education $6^{\text {th }}$ Conference

beyond those who were able to attend. This special edition brings together a selection of papers delivered at the conference. Read, enjoy, discuss, and learn... 